\title{
UNA DIMENSIÓN REAL CON VIDA PROPIA: EL ESPACIO-TIEMPO MÍTICO Y SU RELACIÓN CON LA CONSTRUCCIÓN HISTÓRICA
}

\author{
A Real Life of its Own Dimension: Mythical Space-Time and \\ its Relationship with the Historical Construction
}

\author{
Julio López Saco \\ julosa.ucv@gmail.com \\ Universidad Central de Venezuela. Venezuela
}

Fecha de recepción: 12/12/2016

Fecha de aceptación: 01/06/2017

RESUMEN: El espacio del mito se revela como formador de imágenes significativas. En él el ser humano es capaz de relacionarse afectivamente con el mundo. Es un espacio imaginario, transcultural e implicativo (no acumulativo como el de la historia), y posee una realidad vivenciable, con una dimensión existencial. Naturalmente, es independiente del espacio geográfico y del contemplado por la física. El espacio mítico es plural: son espacios cualitativamente análogos, no pensados, pero si experimentados. En forma de células aisladas se interrelacionan, sin embargo, entre sí. El tiempo mítico, por su parte, es prístino y fundacional. Es una temporalidad no explicativa fundamentada en simultaneidades, que es presentificadora, pues en el momento en que el mito es contado se hace actual y se lleva a cabo, en una suerte de permanencia todo-temporal. Por tanto, no se puede calificar de duración, sino como una actualización.

Palabras clave: mito; espacio; tiempo; simultaneidad; imaginación.

ABSTRACT: The space of the myth is revealed as significant imager. The human being is able to emotionally relate to the world. It is an imaginary, cross-cultural and implicative space (not cumulative as the history), and possesses a reality experienced an existential dimension. Naturally, is independent of the space geographical and of the contemplated by the physical. The space mythical is plural: are spaces qualitatively similar, not intended, but if experienced. In the form of isolated cells they interrelate, however, each other. The mythical time, for its part, is pristine and foundational. It is a not explanatory temporality based simultaneities, which is do this, because at the time that the myth is 
told it is current and is carried out, in a sort of total-temporal permanence. Therefore not be you may qualify of duration, but as an update.

Keywords: myth; space; time; simultaneity; imagination.

SUMARIO: 1. Introducción. 2. El espacio mítico-imaginario. 3. Temporalidad fundacional y relaciones espaciales. 4. Conclusión. 5. Bibliografía.

\section{INTRODUCCIÓN}

En las culturas antiguas el contexto mitológico representó el punto inicial de la literatura y la filosofía, abonando el terreno de las primeras formas poéticas y religiosas. Algunas de las particularidades del pensamiento mítico arcaico, como el predominio de lo concreto, su carácter figurado-sensible y emotivo, y su tendencia hacia modelos de orden sagrado que pueden, y deben, ser imitados, se repiten en determinados ambientes sociales, incluso en la cultura de masas occidental ${ }^{1}$. Esta serie de singularidades derivan del hecho de que el hombre arcaico no lograba separarse completamente del mundo natural, transfiriendo sus propias cualidades a los objetos naturales y dotándolos de pasiones, rasgos humanizantes y vida propia.

Una comparación metafórica entre objetos de la naturaleza y culturales llevó hacia el simbolismo mítico, a concebir el Cosmos en términos zoomorfos o antropomorfos, y a identificar micro y macrocosmos, en particular, en lo tocante al tan habitual isomorfismo entre las partes o componentes del cuerpo humano y las relaciones del espacio. Un sincretismo espacio-temporal es expresado en el isomorfismo de la estructura del espacio cósmico y de los hechos del tiempo mítico; en este sentido, el mito «modela» el mundo real a través del relato de los orígenes de las partes que lo componen.

El ámbito emocional e intuitivo humano es objetivado por el mito de modo simbólico, estableciéndose este como una forma de sistematización creativa, una "conciencia» mítica, de conocimiento de la realidad, metaforizada a través del modo de pensar mitológico. El espacio mítico, estructural, no funcional, mantiene conexiones estáticas y relaciones que se fundamentan sobre una identidad

${ }^{1}$ Se alude aquí al pensar mítico, y no únicamente a un tipo de discurso, en cuanto a su esencia imaginativa, espontánea, creativa, con tendencia a sintetizar y a generalizar, en lugar de analizar y especializar. En consecuencia, un pensar unificador y estructurante del conjunto, no expresionista, absteniéndose de fracturar la experiencia. Metafórico y secuencial, demanda una atención sostenida. Aunque lejos de ser sistemático y analítico, actúa como un conjunto de "nociones», como ideas recibidas (basadas en la tradición o la conveniencia), que «interpretan» la realidad. Sobre las demandas del Homo Mythologicus es recomendable Brockway, R. W. (1993). Myth. From the Ice Age to Mickey Mouse. Albany: State University of New York Press, en particular, pp. 6-10. 
primordial a partir de la percepción que el hombre tiene de sí mismo, por lo que el Cosmos se concibe como construido según un único modelo, bien reflejado en aquellos mitos, prototípicos, que hacen surgir el mundo de las partes del cuerpo humano (Pan Gu, Purusha, Tiamat, Ymir, Ptah, entre otros varios más).

Las culturas tienen tendencia a ofrecer un simulacro de seguridad al futuro de la colectividad haciendo repetitivas las actividades primordiales, muchas de ellas con fundamento mítico, haciendo así el futuro previsible, al conformarlo a un pasado recuperable por su ejemplariedad. Lo imaginario y lo mítico remiten a una particular condición, la de la posibilidad, porque si bien esta es inconcebible, hace, no obstante, posible pensar, preparando así, y precediendo, al pensamiento (Lancskowski, 1972, pp. 282-309; Lessa y Vogt, 1965, pp. 152-154; Coca, 2008, p. 60). Ello implica, si se sigue este sendero, un mito que precede y no puede ser pensado, o puede serlo desde aproximaciones y acercamientos ciertamente inacabables. Como facultad humana es capaz de dibujar la forma que delimita y diferencia el horizonte práctico, estimulando las directrices individuales y colectivas, y conformándose como el embrión del sentido humano, expresado de múltiples maneras: estética, política, social o económicamente.

\section{EL ESPACIO MÍTICO-IMAGINARIO}

El espacio imaginario, esencialmente mítico, se convierte, para algunos teóricos (Merleau-Ponty, 1979, pp. 15-18; Bachelard, 1969, pp. 10-11; Arruda, 2004, p. 5), en la fuente donde se forman las imágenes y se estructuran las ideas. Se trata de un espacio propio, construido a partir del hombre en sus relaciones con el mundo, en la posesión del mundo por el sujeto a través de su propio cuerpo (véase más abajo). Tal comunicación del sujeto con el medio que le rodea, con el "Universo», se torna afectiva, anterior al pensamiento reflexivo, lo que significa que es una estructura pre-reflexiva y no objetiva, una especie de experiencia originaria, ni antilógica ni irracional, que permite captar un sentido latente y difuso que, para ser aprehendido, no necesita ser definido. Hay aquí la implicación de un conocimiento del mundo, un saber latente pleno de sentido, que se vivencia y no se puede explicar.

Esta, se diría, experiencia originaria (participación mística de Lévy-Bruhl, la pregnancia simbólica de E. Cassirer, o la primacía de los esquemas de G. Durand ${ }^{2}$ ), dentro del espacio imaginario mítico se caracteriza, en consecuencia, por la simultaneidad de forma y contenido (Lévy-Bruhl, 1978, pp. 10, 12, 78 y ss.; Durand, 1981, pp. 35-39 y ss.; Cassirer, 1997, pp. 45 y 58 y ss.). En este sentido, las imágenes del mito, como aquellas del arte, simbólicas, no tienen una relación de signo a

2 Primacía de los esquemas según la cual a un lenguaje expresivo y corporal humano, presemiótico, le sucede la gramática y el léxico. 
significado, no son analógicas, ni tienen una fuente propia de significado que les sea específicamente inherente. Son imágenes que implican una modalidad de existencia propia.

Los espacios antropológicos, mítico-imaginarios, se perfilan como independientes, en cuanto al origen de su producción, del espacio físico y geográfico, donde el hombre transita junto a cosas, objetos y animales, en sus relaciones mundanas. Este espacio, imaginario y transcultural, no es mera apariencia confusa de un espacio verdadero, único y objetivo, a fin de cuentas un constructo intelectual, sino que posee una realidad vivenciada, con unas dimensiones existenciales que lo convierten en espacio sacro.

En cualquier caso, se debe destacar con claridad, no obstante, que el espacio antropológico solo existe en términos de una relación con el espacio objetivo, pues es la vinculación entre los términos la que ofrece, en definitiva, una orientación referencial. La orientación direccional espacial se asociará a la dicotomía sagradoprofano y a la polaridad antinómica día-noche o luz-oscuridad, conformándose así un espacio geometrizante, palpable de manera sistemática en China, Grecia o India (Lewis, 2006, pp. 86-104; Gómez Espelosín, 2000 y 2013; Wulff Alonso, 2008, passim), que distinguen centro (ordenado, jerarquizado y culto), de periferia (salvaje, natural e incivilizada).

El espacio mítico se despliega entre el simbólico, con su posibilidad de entender un orden cósmico independiente de los particulares sensibles, y el de acción, que depende de la agudeza visual y se alinea con el espacio orgánico y de percepción. En él no se distingue posición y contenido, que demandaría un aquí y un allí desde todos los contenidos particulares sensibles. Las categorías del espacio funcionan para unificar la diversidad de experiencias en un conjunto estructurado y articulado que vincula macro y microcosmos en un modelo o patrón coherente.

El espacio no es el vacío geométrico de Euclides; resulta ser, en realidad, un conjunto de lugares que son homólogos y análogos cualitativamente. En tal sentido, se trata de una extensión vital homologada en series asociativas, simpáticas o no, capaces de captar todas las extensiones, hacia arriba, abajo, a la derecha, izquierda, o hacia adelante o hacia atrás. Hablamos de un espacio vivido y experimentado, no pensado, cuya inmensidad se constituye, de modo discontinuo, como un cúmulo de verdaderas islas que tejen correspondencias (Durand, 1999, pp. 50-51).

En el desarrollo de la espacialidad mítica, la organización del mundo se mueve, entonces, desde un centro, ubicado en la eficacia del cuerpo humano, a los cuerpos astrales como lugares poderosos que determinan zonas o sectores del espacio universal. El tiempo mítico-simbólico conoce diversos estratos de duración. La regionalización de un mismo tiempo posibilita la reintegración del pasado y una continua profetización. Los tiempos, así, meteorológico, astronómico y existencial, no dejan de ser hojas del mismo libro. 


\section{TEMPORALIDAD FUNDACIONAL Y RELACIONES ESPACIALES}

La concepción mítica sobre el tiempo implica, por su parte, una génesis formativa, un tiempo fundacional-primordial que se convertirá en tiempo empírico y real por mediación de las relaciones espaciales básicas, determinadas por sus ejes esenciales, verticales norte-sur y horizontales este-oeste. La percepción mítica del tiempo biológico, visto como un ciclo vital, pudo ser previo a la intuición del tiempo cósmico, concebido también como un «proceso vital». Su vinculación mutua, en forma de movimiento de las formas subjetivas de la vida humana hacia la intuición objetiva de la naturaleza, daría lugar a la mencionada relación macro-microcósmica, en la que los fenómenos naturales, en especial los astros, se convertirán en signos del ordenamiento universal.

A la par que esto ocurre, el tiempo confiere al ser un carácter también regulador y ordenador, con lo que el nexo entre el Cosmos astronómico y ético se hace evidente, en particular por medio de la actuación de los héroes culturales y reyessabios virtuosos ${ }^{3}$. De este modo, en el mito el hombre será contemplado como un todo con los elementos de la realidad, afianzándose un sentimiento de unidad e identidad con animales y vegetales, que es un referente fundamental en muchas mitologías, como las chinas, la de Egipto y, en menor medida, la griega e hindú.

Los mitos, complejas metáforas en sí mismos, muestran unos senderos de pensamiento sobre el tiempo que son implícitos más que definidos. Tiempo y espacio se entretejen: la escala temporal alterada o irreal, que implica el «erase una vez", conlleva unos espacios que son verdaderos momentos fuera del tiempo (como la noción de Paraíso o el Período del Sueño de los aborígenes de Australia). Esta paradoja tiene mucho en común, sin embargo, con la visión del tiempo por los físicos, para quienes el tiempo no es una progresión inmutable sino un factor en un modelo de espacio-tiempo de causalidad y determinismo relativista. Es por eso que la cosmología de la física moderna aparece muy cercana a la mitológica (Lincoln, 1992, pp. 26-50; Trubshaw, 2003, pp. 33-34) ${ }^{4}$. Pensar sobre el tiempo no es algo

${ }^{3}$ El pensamiento mítico, concentrado en problemas metafísicos, se orienta hacia una finalidad armonizadora: del individuo con la colectividad, pero, sobre todo, del grupo social con el ambiente natural. Como el mito explica y sanciona el orden cósmico y social, al explicar qué es el mundo y quién es el hombre, lo que hace es reforzar el ordenamiento existente e incorporar al individuo a la colectividad, insertándolo en el movimiento circular de lo tribal y de la naturaleza. El mito remite lo esencial de todo a su origen: describir el mundo es igual que el relato de la historia de la creación. Objetos naturales y culturales deben su existencia a hechos ocurridos en un lejano tiempo mítico, en un "pasado" que es la época de la creación primordial, prístina, fundacional, un depósito de prototipos, de fuerzas que mantienen el orden natural y social. Véase al respecto Meletinski, E. M. (2001). El Mito. Literatura y folclore. Madrid: edit. Akal, en específico, pp. 46-47 y ss.

${ }^{4}$ En el lenguaje de la cosmología moderna encontramos la presencia de «personajes» casi propiamente míticos, entidades enigmáticas y casi no detectables, como la materia oscura, los 
natural, sino que parece una reverberación de mitos profundamente asentados que estructuran nuestro pensamiento.

Lo mítico, en realidad, es presente. Quien oye o lee un relato mítico es transportado al tiempo del suceso (Dardel, 1984, p. 233) ${ }^{5}$. Como lo mitológico actualiza cada cosa, el oyente es un testigo directo de un mundo "presente». El evento, al contarse, se realiza; es una suerte de presentemente realizado. Así, bien en su imagen o en su narración, el mito transmite una experiencia de perennidad vital. El tiempo mítico es un repetido ahora, no una duración, sino una actualización, un tiempo hecho o tejido a base de simultaneidades. La tendencia, entonces, de un ahora a otro, es la «eternalización». Este peculiar presente hace hervir las profundidades afectivas del ser, ignorando las abstracciones de nuestra temporalidad. De este modo es como el ser humano se siente unido a todo lo vivo.

El tiempo, denominado en ocasiones como rizomático o kairológico, del momento relevante, representa una simultaneidad de ritmos entrelazados de manera compleja, que son reversibles. Es un tiempo no explicativo. La historia se plantea una memoria escrita acumulativa que incorpora y, en consecuencia, acumula, nuevos acontecimientos relacionados con el sujeto histórico y con sus intereses. Por el contrario, en el tiempo mítico la simultaneidad ya referida permite cierta reversibilidad de la sucesión y contextualizar una sincronía particular con otros hechos previos, paralelos o incluso, posteriores.

En Heródoto y en Tucídides, aun con la instalación de una retórica comprensiva del conjunto de acontecimientos elegidos por medio de causas explicativas, todavía encontramos narraciones de las gestas de los héroes para que sus hazañas gloriosas perduren en la posteridad. En este sentido, la temporalidad en ambos muestra su relación mítica con el eterno retorno, al buscar que lo narrado perdurase para siempre (Calame, 1996, p. 139 y ss.; Hunter, 1982, pp., 86-92; Eliade, 2011, pp. $45-48$ y ss.). La tendente circularidad temporal mítica corresponde a las acciones humanas cotidianas, aquellas, por ejemplo, que inician y finalizan una rutina diaria, pero sobre todo a las acciones trascendentales (vuelta al seno materno, la tumba para «renacer»). Todo ello remite, naturalmente, a la totalidad, referente simbólico del círculo (Campbell, 1991, pp. 520-521). La construcción narrativa de la historia, sin ir más lejos, se lleva a cabo, en cualquier caso, desde la imaginación, la cual permite al historiador enlazar los hechos desde el presente al pasado, recontándolo.

En las sociedades arcaicas tradicionales, la comprensión del tiempo suponía, por tanto, creer en poderosas y misteriosas fuerzas que gobernaban, circularmente,

vacíos expansivos, que impulsan el resto de cosas, o los famosos agujeros negros. Véase Arnau, J. (2012). Cosmologías de India. Védica, sámkhya y budista. México, D.F.: edit. F.C.E., en especial, pp. 14-15.

${ }^{5}$ La palabra aquí no es un mero discurso; es una fuerza, de la que emana el poder para pensar, actuar, construir. A través de ella el hombre encara el mundo, existe y conoce. 
las cosas por siempre, por lo que estaba cargado de valores emocionales. Era un tiempo contemplado con presencia simultánea y de carácter trascendente y perfecto. Con la tragedia griega y, ya posteriormente, con la cultura hebrea, la linealidad temporal desalojó a la eternidad, dejando paso a una finalidad concreta, habitualmente la muerte. Sin embargo, todavía Platón identificaría el tiempo con el movimiento circular. Los prototipos míticos primitivos reflejaban modelos recurrentes en la naturaleza, episodios periódicos en el mundo vivido y la repetición de comienzos primigenios.

Los pensadores griegos arcaicos emplearon este paradigma cíclico, donde los períodos mundanos podrían surgir y caer, y ser seguidos por recurrencias inmediatas en una sucesión sin fin, lo que supone concebir al tiempo no como un aspecto simple de la realidad, sino como una constitución de la naturaleza de las cosas, como un proceso de cambio y llegar a ser, emergencia, aparición y desaparición de las formas ${ }^{6}$. Este énfasis en el tiempo como proceso se conecta con la tradición mítica, por ejemplo con la religión dionisíaca y la poesía trágica.

El tiempo mítico ocurre siempre para algo y, como el espacio, es cualitativo, no cuantitativo. Las relaciones e identidades míticas permiten que diferentes cosas o aspectos surjan y se interrelacionen si exhiben similitudes situacionales, funcionales o afectivas. Pasado y futuro no se separan ni se hacen distantes del presente. El tiempo mítico, es, por tanto, vivido, fenomenológicamente anterior al del reloj, psicologizado, como se evidencia todavía cada día en nuestras propias experiencias cotidianas. Se trata de un tiempo concreto, situacional e impreciso (Heidegger, 1962, sec. 78-82) ${ }^{7}$. Se ha dicho que el mito trasciende tiempos, futuro, presente y pasado. Siempre se presentifica, tanto en el ya como en el no todavía; esto es, en el aquí y ahora, a través de sus reactualizaciones. Se convierte así en una exploración del mundo que ofrece nuevos sentidos potenciales que apuntan al pasado y desde el presente al futuro, potencialidades que se pueden evidenciar por medio del lenguaje y la propia historia.

El tiempo mítico se caracteriza por su amplitud y por su carácter englobante, que instituye la historia, fundando el tiempo humano y dándole sentido vital.

${ }^{6}$ El modelo lineal temporal, cristalizado en la tradición cristiana tardía, concibe un tiempo irreversible e irrepetible, cuyo curso va desde un comienzo absoluto a un final total, lo que implica que el tiempo es inferior a una eternidad intemporal que resuelve la negatividad de la temporalidad. Sobre la temporalidad en la cultura de la Grecia antigua puede verse Hatab, L. J. (1990). Myth and Philosophy. A Contest of Truths. Chicago: edit. Open Court, sobre todo, pp. 192-193.

${ }^{7}$ Las distracciones cotidianas, como el teatro, el cine (sobre todo de aventuras, el western), la lectura (particularmente novela, poesía y cómic), y los juegos de azar, logran el aislamiento, la distracción (en el sentido de la huida), del tiempo real, cotidiano y común, para sumergirse en una atemporalidad o primer tiempo (mitificador). En esas distracciones encontramos los nuevos héroes y dioses de nuestro tiempo, políticos, deportistas, cantantes o actores, por ejemplo. 
Aunque nada se explique, se introduce la exterioridad. El ritual establece el tiempo estructural del tiempo profano. La estructura de la conciencia mítica conlleva, hay que destacarlo, una pobreza del tiempo objetivo y categorial, pero el mito lo suple con una organización del tiempo global y comunitario, un principio cronométrico que es sustancia de lo real. Entre la marca fundante del tiempo sacro y la dispersión de la existencia se ubicaría el esquema calendárico (Cruz Cruz, 2007, pp. 45-46; Gusdorf, 1983, pp. 72-75) ${ }^{8}$. En el universo mítico el monismo ontológico predomina sobre la disgregación empírica de la representación; esto es, el tiempo primordial salvaguarda la plenitud ontológica, siendo el tiempo festivo el que actualiza esa gran temporalidad prístina, asociándolo al tiempo ordinario. El espacio mítico, por su parte, es estructural e implicativo, en virtud de que en cada parte se refleja el todo. No es un espacio de dispersión y de exterioridad, sino de carácter totalizante, y se suscita desde dentro más que se determina desde el exterior.

Así pues, el mito sucede en un tiempo transtemporal, dominador de la completa extensión del tiempo temporal. En tal sentido, sería el tiempo de la total presencia. Como lo mítico actualiza todo, acaba siendo un presente, sin pasado o futuro, una especie de modelo perdurable, perpetuo (Lévi-Strauss, 1971, p. 225; Vitsaxis, 2006, p. 19).

En la temporalidad mítica, la unidad temporal del mundo es aprehendida como una suerte de tiempo biológico, un flujo y reflujo rítmico de vida. Así, cada "porción» del mundo parece tener su tiempo propio: los rituales de la cosecha pertenecen al fin del verano como una posesión esencial de esa estación; los eventos son expresiones naturales de la esencia y la eficacia del ritmo y pulso del proceso cíclico anual. En tal sentido, en el mundo mítico no existe una concepción de un orden temporal simple secuencial y sucesivo al que todos los acontecimientos se vinculen. Es por ello que los ritos no conmemoran eventos del pasado, sino que "crean» aquellos eventos en el presente. El tiempo mítico entonces, procede de la identificación ser humanoproceso de la naturaleza, sin que existan categorías ideales. Posee y hace acopio de las apariencias cambiantes en el mundo y, por ello, es el inverso al tiempo empírico. Mientras en este, las cosas y sucesos son sometidos a un orden temporal general, en el mítico es el tiempo el sometido a las cosas y hechos mismos. El proceso universal temporal no es entendible por la conciencia mítica, pero sí por la religiosa (como puramente espiritual) y por la científica (como puramente ideal) (Baeten, 1996, pp. 69-73 y ss.; 126-129).

8 El calendario se entendería como un eterno retorno periódico de gestas divinas ritualmente consagradas. El tiempo astronómico y de la historia geológica es, a su vez, en virtud de su carácter casi inconmensurable, mítico, pues lo metaforizamos para asimilarlo y dotarlo de sentido profundo, a pesar de que podamos manejarlo con variables intelectuales numéricas. El mito es forma de representación y régimen de acción. En consecuencia, su épica y pathos de identificación vivencial se complementa con el drama ritual. 
El tiempo mítico posee sus zonas temporales, cada una con su propio pulso rítmico, algo análogo a los campos de fuerza, en los que la integridad de algo se pierde al moverse, al recrearse o renovarse (como ocurre con el año nuevo). La más arcaica aprehensión temporal surge de los ritmos biológicos y sensibles, así como de las periodicidades propias de la observación natural (día-noche), lo que presupone un tiempo como una clase de musicalidad, con tempos variados de existencia orgánica. El mito determina las manifestaciones temporales del mundo a través de la proyección de cambios y ciclos. El espacio mítico se constituye y se experimenta como una clase de espacio esférico elástico en el que las localizaciones nunca se determinan en relación a otras. El tiempo es, pues, periódico y rítmico, un pulso insistente del mundo de cambios y de llegar a ser; nada se determina como pasado o futuro en relación a un presente constantemente en movimiento. Esta concepción se antoja sugerentemente cercana al espacio-tiempo de la física contemporánea (Lozev, 1998, pp. 76-77 y ss.; Harpur, 2007, p. 197).

\section{CONCLUSIÓN}

Los mitos, como relatos referidos a actuaciones siempre memorables en un tiempo más que lejano, prestigioso, tienen lugar en un mundo antiguo. No obstante, en tiempo y lugar se extienden hasta la actualidad presente.

En el espacio imaginario mítico, transcultural y no aparente, la experiencia originaria se caracteriza por simultaneidades, tanto de forma como de contenido, expresándose, y experimentándose, una realidad vivida. Del mismo modo, la temporalidad mítica presenta una compleja simultaneidad de ritmos entrelazados que permiten sincronías (paralelas o con acontecimientos anteriores o posteriores), facilitando la posibilidad de la reversibilidad. Estamos ante una circularidad temporal, propia de la eternidad, en lugar de la linealidad, que convierte a los mitos en prototipos modélicos repetitivos, ritualmente actualizables. El tiempo del mito trasciende tiempos y siempre se presentifica. Su ejecución es transtemporal, en el sentido de que en la esfera del mito no sucede un orden temporal simple, secuencial y sucesivo, al que los acontecimientos se vinculan.

El espacio-tiempo de un mito sería el equivalente a un escenario en el que acontece dicho mito. Estaría compuesto de una serie de unidades espaciotemporales, muy semejantes a las distintas escenografías de una pieza teatral. Relato y escenario conforman, entonces, una unidad. Tiempo y espacio se imbrican, por lo tanto, en una íntima relación de identidad, rítmica y dinámica. El tiempo, como el espacio, en fin, tiene pliegues, grietas y de ahí la posibilidad de la reversibilidad en la esfera mítica. El tiempo mitológico sería el devenir alógico (o mejor, extralógico) de la eternidad, de modo semejante a como la misma eternidad es el devenir alógico de la idea extratemporal. 
Los espacios míticos, momentos fuera del tiempo, destilan una magia, un poder evocativo, una fuerza imaginativa tan poderosa que llegan a convertir a los relatos en «historias» que, además de deleitar, enseñan ejemplarmente. De ahí que su poder de atracción no escape a nadie en ningún momento de su vida. La amplia gama de potenciales nuevos sentidos que los mitos destilan pueden llegar a ser evidenciados por la historia. En tal sentido, uno y otra configuran una hermandad de sangre indisoluble.

Es probable que el folclore (¿una mitología institucionalizada?) sea remoto en el espacio, pero el mito lo es en el tiempo (transmitido por los ancestros). En cualquier circunstancia, no se trata de una lejanía literal, sino de una metáfora que indica, expresivamente, la enorme profundidad de las raíces de los mitos, re-imaginados a sí mismos de continuo fuera del espacio y el tiempo.

\section{BIBLIOGRAFÍA}

Arnau, J. (2012). Cosmologías de India. Védica, sámkhya y budista. México, D.F.: edit. F.C.E.

Arruda, F. (2004). A Transgressâo como fundamento do espaço imaginario. En Anais do XIII Ciclo de Estudos sobre O Imaginário (pp.1-19). Recife, Brasil.

Bachelard, G. (1969). La psychanalise du feu. París: edit. Gallimard.

Baeten, E. M. (1996). The Magic Mirror. Myth`s Abiding Power. Albany: State University of New York Press.

Brockway, R. W. (1993). Myth. From the Ice Age to Mickey Mouse. Albany: State University of New York Press.

Calame, C. (1996). Mythe et histoire dans l'Antiquité grecque. Lausanne: Université de Lausanne.

Campbell, J. (1991). El poder del mito. Barcelona: edit. Salamandra.

Cassirer, E. (1997). El mito del Estado. México, D.F.: edit. F.C.E.

Coca, J. R. (Ed.) (2008). Las posibilidades de lo imaginario. Barcelona: edit. del Serbal. 
Cruz Cruz, J. (2007). Sentido antropológico del mito: Pamplona: edic. Universidad de Navarra.

Dardel, E. (1984). The Mythic. En A. Dundes (Ed.), Sacred Narratives. Readings in the Theory of Myth (pp. 225-242). Berkeley: University of California Press.

Durand, G. (1981). Las estructuras antropológicas de lo imaginario. Una introducción a la arquetipología general. Madrid: edit. Taurus.

Durand, G. (1999). Ciencia del hombre y tradición. Barcelona: edit. Paidós-Orientalia.

Eliade, M. (2011). El mito del eterno retorno. Arquetipos y repetición. Madrid: Alianza edit.

Gómez Espelosín, F. J. (2000). El descubrimiento del mundo. Geografía y viajeros en la antigua Grecia. Madrid: edit. Akal.

Gómez Espelosín, F. J. (2013). Memorias perdidas. Grecia y el mundo oriental. Madrid: edit. Akal.

Gusdorf, G. (1983). Mythe et metaphysique. París: edit. Flammarion.

Harpur, P. (2007). Realidad Daimónica. Girona: edit. Atalanta.

Hatab, L.J. (1990). Myth and Philosophy. A Contest of Truths. Chicago: edit. Open Court.

Heidegger, M. (1962). Being and Time. Nueva York: edic. Harper \& Row.

Hunter, V. (1982). Past and Process in Herodotus and Thucydides. Princeton: Princeton University Press.

Lancskowski, G. (1972). Nevere Forschungen zur Mythologie. Saeculum, 19(2-3), 282-309.

Lessa, W. A. y Vogt, E. Z. (Eds.) (1965). Reader in Comparative Religión. An Anthropological Approach. Nueva York: edit. Harper \& Row.

Lévy-Bruhl, L. (1978). La mitología primitive. Barcelona: edit. Península. 
Lévi-Strauss, C. (1971). The Structural Study of Myth. En T. A. Sebeok (Ed.), Myth: A Symposium (pp. 206-231). Bloomington: Indiana University Press.

Lewis, M. E. (2006). The Construction of Space in Early China. Albany: State University of New York Press.

Lincoln, B. (1992). Places outside space, moments outside time. En E. C. Polomé (ed.), Homage to George Dumézil, Journal of Indo-European Studies, 3, 26-50.

Lozev, A. (1998). La dialéctica del mito. Bogotá: T. M. Editores.

Meletinski, E. M. (2001). El Mito. Literatura y folclore. Madrid: edit. Akal.

Merleau-Ponty, M. (1979). Le visible et l' invisible. París: edit. Gallimard.

Trubshaw, B. (2003). Explore Mythology. Loughborough: edit. Albion Press.

Vitsaxis, V. (2006). Myth and the Existential Quest. Boston: Somerset Hall Press.

Wulff Alonso, F. (2008). Grecia en la India. Madrid: edit. Akal. 